\title{
DERMATOGLYPHICS OF TWO FETUSES WITH TRISOMY 21 DIAGNOSED BY AMNIOCENTESIS
}

\author{
Michio OKaJIma, ${ }^{1}$ Hiroko IKEUCHI, ${ }^{2}$ and Akira TonOMURA ${ }^{2}$ \\ ${ }^{1}$ Department of Forensic Medicine, Tokyo Medical and Dental University, \\ Tokyo, 113 Japan \\ ${ }^{2}$ Department of Cytogenetics, Tokyo Medical and Dental University, \\ Tokyo, 113 Japan
}

Summary Dermatoglyphic examinations were undertaken on the dermal surfaces of two fetuses at the 20th and 22nd week, respectively, from the onset of the last menstrual periods. The fetuses were diagnosed as cases of trisomy 21 by amniocentesis, and abortions were induced.

Although the dermatoglyphics of the fetus have been studied by some workers (Miller, 1968; Okajima, 1975), dermatoglyphic examinations have not been widely applied in fetuses with chromosomal anomalies. In a comprehensive study on spontaneous abortuses and stillbirths, Poland and Lowry (1974) observed dermatoglyphic features typical of some trisomies in three stillborn infants in which karyotyping was not successful. However, they recognized that dermatoglyphic analysis was difficult in many cases due to maceration of the skin. Recently, Suzumori (1980) reported his dermatoglyphic findings in five fetuses with different chromosomal aberrations karyotyped by amniocentesis.

The present report describes the dermatoglyphic data obtained in two fetuses in which karyotypes were determined as trisomy 21 by amniocentesis.

\section{MATERIALS AND METHODS}

The pregnancies were artificially terminated due to the results of karyotyping by amniocentesis at the 137th day from the onset of the last menstrual period in Case 1 and at the 152nd day in Case 2. The karyotypes of both fetuses were reaffirmed after abortion by the culture of skin fibroblasts. The fetuses were fixed with $10 \%$ formalin after autopsy, and then the hands and feet were delivered to us for dermatoglyphic examination. 
First, one hand and foot of each fetus were prepared for the examination by the author's original method (Okajima, 1975), i.e., the specimens were incubated in $3 \%$ potassium hydroxide solution at $30^{\circ} \mathrm{C}$ for 15 hours and, after preservation in $10 \%$ formalin for several days, the epidermis was removed by brushing with a cotton swab. The other hand and foot of each fetus were treated by a revised method, i.e., the treatment with alkaline solution was repeated with the same procedure after the first manipulation. The revised method yielded a dermal surface of better quality for the analysis. The exposed dermal surface was stained with $0.05 \%$ toluidine blue solution, and the ridges were inspected under a stereomicroscope.

\section{DERMATOGLYPHIC RESULTS}

Case 1 was a male fetus karyotyped $47, X Y,+21$. The crown-rump length was $150 \mathrm{~mm}$, the hand length, $27 \mathrm{~mm}$ and the foot length, $32 \mathrm{~mm}$. The dermatoglyphic findings are shown in Fig. 1 and summarized in Table 1. On the fingertips, there were four ulnar loops and six whorls. The total finger ridge count was about 121 . On both palms, the axial triradius was situated proximally, and, in the interdigital area III, there was a loop pattern. An extra triradius $d^{\prime}$ existed on the right palm. Typical simian creases were observed bilaterally. These were also clearly distinguishable before the hand was treated with the alkaline solution. The digit V bilaterally comprised two interphalangeal creases, but the middle phalanx was apparently shorter than the usual length. On the sole, arch tibial was present bilaterally in the hallucal area. The ridges were sharp and of a linear nature on the entire volar

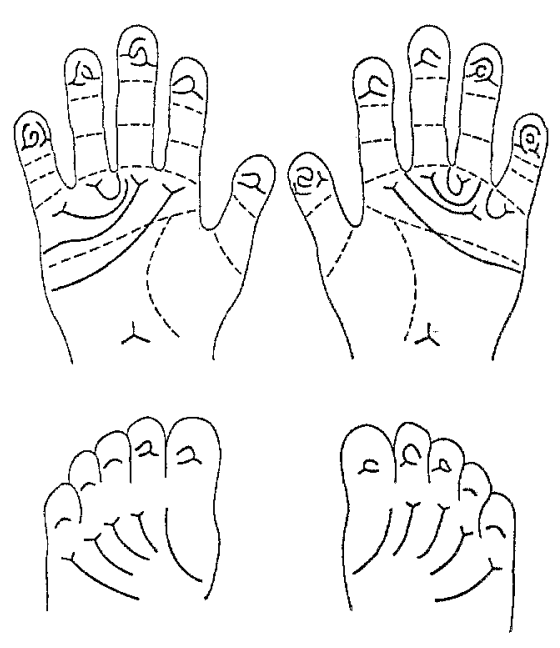

a
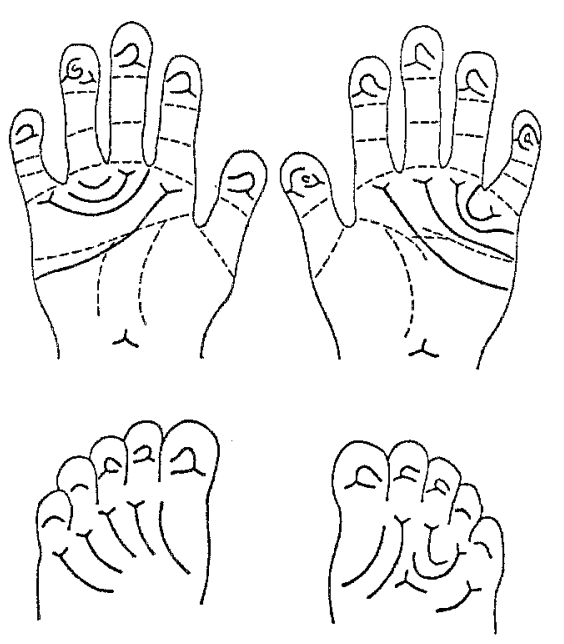

b

Fig. 1. Dermatoglyphic configurations. a, Case 1; b, Case 2. 
Table 1. Fingertip patterns and ridge counts of the two fetuses with trisomy 21 .

\begin{tabular}{ccccccccccccc}
\hline & \multicolumn{1}{c}{ Right } & & \multicolumn{4}{c}{ Left } & & Total finger \\
& I & II & III & IV & V & & I & II & III & IV & V & \\
ridge count \\
Case 1 & W & U & U & W & W & & U & U & W & W & W & \\
& $15-9$ & $10-0$ & $10 ?-0$ & $3-14$ & $17-13$ & & $6-0$ & $14-0$ & $12-5$ & $5-8 ?$ & $15 ?-9$ & about 121 \\
Case 2 & W & U & U & U & W & & U & U & U & W & U & \\
& $17-12$ & $17-0$ & $20 ?-0$ & $18-0$ & $13-2$ & $22-0$ & $17-0$ & $17-0$ & $19-12$ & $10 ?-0$ & about 170 \\
\hline
\end{tabular}

$\mathrm{U}$, ulnar loop; W, whorl. Uncertain ridge counts marked '?' were due to mechanical injuries.

surface, without suggesting the dissociation which is expressed as hypoplastic or dotted lines and often observed characteristically in patients with Down syndrome.

Case 2 was a female fetus karyotyped $47, \mathrm{XX},+21$. The crown-rump length was $155 \mathrm{~mm}$, the hand length, $31 \mathrm{~mm}$ and the foot length, $39 \mathrm{~mm}$. As shown in Fig. 1 and Table 1, there were seven ulnar loops and three whorls on the fingertips. The total finger ridge count was about 170 . On both palms, the axial triradii were located proximally. The interdigital triradius $c$ was absent on the left palm. A typical simian crease was present on the left palm, and a transitional one on the right palm. The digit $\mathrm{V}$ bilaterally comprised two interphalangeal creases, but the middle phalanx was shorter than the usual length. On the sole, the hallucal area bilaterally presented arch tibial. The ridges were sharp, and a hint of dissociation was not apparent.

In the present cases, some of the dermatoglyphic features outlined above are types that occur more frequently in Down syndrome (Matsui, 1978; Matsui et al., 1966; Shiono et al., 1969; Schaumann and Alter, 1976), whereas some other features characteristic of this syndrome, such as distal displacement of the axial triradius, were not observed. The appearance of the ridges did not seem to be unusual.

It was revealed from the above observations that examination of dermatoglyphic configurations as well as ridge counting can be performed on the dermal surface even in a fetus at about 20 weeks with a chromosome anomaly. However, further attempts should be made to make precise comparisons of the structure of the dermal ridges in anomaly cases with that of normal fetuses at the same developmental stages.

\section{REFERENCES}

Matsui, I. 1978. Dermatoglyphics and congenital abnormalities. Shoni-Igaku (in Japanese) 11: $814-868$.

Matsui, I., Nakagome, Y., and Higurashi, M. 1966. Dermatoglyphic study of Down's syndrome in Japan. Paediat. Univ. Tokyo No. 13: 43-48.

Miller, J.R. 1968. Dermal ridge patterns: Technique for their study in human fetuses. J. Pediat. 73: $614-616$.

Okajima, M. 1975. Development of dermal ridges in the fetus. J. Med. Genet. 12: 243-250.

Poland, B.J., and Lowry, R.B. 1974. The use of spontaneous abortuses and stillbirths in genetic counseling. Am. J. Obstet. Gynecol. 118: 322-326. 
Schaumann, B., and Alter, M. 1976. Dermatoglyphics in Medical Disorders. Springer, New York.

Shiono, H., Kadowaki, J., and Kasahara, S. 1969. Dermatoglyphics of Down's syndrome in Japan. Tohoku J. Exp. Med. 99: 107-113.

Suzumori, K. 1980. Dermatoglyphic analysis of fetuses with chromosonal abnormalities. Am. J. Hum. Genet. 32: 859-868. 